\title{
Psychosocial Risk Factors Among Slovene Professional Drivers
}

\author{
Danica Murko \\ The Ministry of Infrastructure, Maribor, Slovenia \\ Maja Meško \\ University of Primorska, Faculty of management, Koper, Slovenia
}

\section{Abstract}

The characteristics of the profession drivers, in the nature of their work, influence the occurrence of various health risk factors. Professional drivers are, in general, exposed to a workspace that is limited, vibrations, uncomfortable seats and forced position meanwhile prolonged sitting. The objective of our study was to investigate psychosocial risk factors among Slovene professional drivers' samples in a crosssectional study. The data collection was performed by the use of a survey questionnaire, which was distributed among professional drivers. The research was conducted on 259 professional drivers; 125 train drivers, 57 bus drivers, 57 truck drivers and 20 other drivers (eg. taxi drives). The cooperation in the survey was anonymous and voluntary. The measurement for coping with psychosocial risks and absenteeism - OPSA was used, which is divided into two parts 1) a general part (which includes sociodemographic and health related information about the employees as well as 2) the part that focuses on employee psychosocial load evaluation. With the use of analysis of variance, we tested wheatear there were statistically significant differences in OPSA statements among mentioned groups of drivers. There is no evidence that the psychosocial risk factors (OPSA profile) are statistically significantly different between specific groups of drivers. However, could be noted that bus and train drivers are the most vulnerability occupational groups among professional drivers.

Keywords: Slovene professional drivers, psychosocial risk factors, absenteeism JEL classification: 112, 131, M12

\section{Introduction}

The characteristics of the profession driver, in the nature of their work, influence the occurrence of various health risk factors. In general are professional drivers exposed to a workspace that is limited, vibrations, uncomfortable seats and forced position meanwhile prolonged sitting (Funakoshi et al., 2003; Louit-Martinod et al., 2016). The result of all this can be problems with spine, malfunctions of organs in the chest area and abdominal cavities. Professional drivers are also exposed to high blood pressure and cardio vascular system diseases due to insufficient blood supply to the lower part of the body caused by prolonged sitting. In addition, professional drivers are often exposed to the locomotor system diseases, for instance the lower spine, as well as to psychological problems (Louit-Martinod et al., 2016; Kresal et al., 2017). Despite the fact that train engine driver is a profession that is seemingly comparable to similar professions in the transport sector, it is associated with specific risks that have a significant impact on their physical and physical health. Train engine drivers perform their work in a seated position, which is why ergonomics of the working environment (cockpit) is important. Due to safety devices (wake-ups), drivers are forced into 
recurrent movements, which additionally contribute to the feeling of monotony, which is a result of long track observation of the track. In addition to electromagnetic waves that have a negative impact on health, they also have a negative impact on the feeling of vibration due to the movement of locomotives along railway tracks (track). In addition to the factors affecting physical health, such us chronic fatigue, musculoskeletal pain and cardiovascular problems, those who have a strong influence on the psychological state and are responsible for the anxiety of drivers (Šprah et al., 2014) are equally important.

National vocational qualification (NRP, 2012) defines the train engine driver's profession as follows:

- organizes and supervises their own work,

- prepare a towing vehicle for safe operation,

- prepare a train for safe driving,

- manages towing vehicles and performs safe and regular driving according to norms, restrictions, prohibitions, orders and warnings, expressed by traffic signalization and traffic-technical regulations,

- independently solves problems and measures in degraded conditions, serious accidents, accidents and incidents,

- keep records and evidences in the transport process,

- carries out the implementation of quality standards,

- communicates with colleagues, superiors, the controller and carrier, and others, and

- regularly monitors and implements the norms for ensuring the safety of traffic, safety at work, fire safety, internal order and environmental protection.

The field of ability and suitability for the performance of the work of executive railway workers, including the driver's profession, is regulated by the Rules on procedures for verifying the mental and physical capacity of executive railway workers (Official Gazette of the Republic of Slovenia, No. 79/2009 and 12/2016). The regulation defines the method, scope, frequency and frequency of verification of the mental and physical capacity of the executive railway workers in accordance with Directive 2007/59/EC (2007) of the European Parliament and of the Council of 23 October 2007 on the certification of train drivers operating locomotives and trains on the Community's rail network (OJ EU L 315), most recently amended by Commission Directive 2014/82/EU of 24 June 2014 amending Directive 2007/59/EC of the European Parliament and of the Council as regards general professional knowledge and health requirements and permit requirements (OJ EU L 184).

The regulation, Directive 2007/59/EC, generally stipulates that an executive railway worker is not able to perform his duties safely when he has a disease, condition, disorder or injury and their influence on the awareness, attention, memory, speed, correctness of the judgment, and the reaction of the impaired physical and mental function, or if there is also the use or alcohol dependence syndrome, use or drug addiction syndrome or other psychoactive substances, unstable heart disease (angina pectoris, complete heart block, AV block of stage II, sore throat syndrome, carotid sinus syndrome or other bradycardic rhythm disorders, irrespective of the mode of treatment; the cardiovascular system capacity is less than 40 percent of the expected capacity (New York Heart Association - Group IV) (The Criteria Committee of the New York Heart Association, 1994); six months have elapsed since the onset of myocardial infarction and has signs of heart failure, has arrhythmia, or has attacks of angina pectoris), episodic and paroxysmal disorder of consciousness, nervous neurological disease with a severe impairment of the function of the organism, mental and behavioural disorders, diabetes, depending on insulin therapy or other illness of 
the internal organs, which could cause sudden disturbance of consciousness, reduced concentration for work, disorders movement, balance and coordination.

Verification of compliance with the health conditions for safe work at the workplace of the executive railway worker is the assessment of compliance between the requirements of the workplace, with a special emphasis on the assessment of the degree of autonomous responsibility of an executive railway worker, which is an integral part of the risk assessment and is produced by the employer and the physical and mental characteristics, the abilities and capacities of the executive railway worker, which influence his safe performance of work. Verification of the fulfilment of health conditions for the Executive Railway worker's job must be comprehensive, with an emphasis on physical and mental health and the requirements for sensory abilities (vision, hearing). The fulfilment of the health conditions of an executive railway worker is assessed and checked by medical examinations.

In addition to the health conditions, in accordance with the Railway Traffic Safety Act "Zakon o varnosti v železniškem prometu. Uradni list RS, št. 56/2013, 91/2013, 82/2015", the driver must also complete the examination of general professional knowledge at a recognized subject (centre) for drivers and drivers of linear vehicles.

The ergonomics of the driver's work space depends on the type of towing vehicle or locomotive it manages. The size of the driver's cab of the railway vehicles, currently used in the territory of Slovenia, is on average $5 \mathrm{~m} 2$. When driving, the driver sits in the direction of driving, and the view is directed straight. When watching instruments, the door is in the neutral position. To observe the occurrence of the train while driving, the driver uses rear-view mirrors, turning the head $45^{\circ}$ to the left and $15^{\circ}$ downwards or $45^{\circ}$ to the right at the eye level. The arms are handled during operation with the handles in the pre-position and lean on the control panel. When the driving speed is achieved and there is no need to handle the manipulative arms, the driver has arms resting on the thighs or on the seat armrests.

The driver's seat is air-spring-loaded and reduces the vibrations on the lower back of the back, which are transmitted from the ground. The backbone has the ability to change the inclination and supports the back from the lumbar to the chest spine; the neck part is not supported. Under the driver's cab, it is 1.7 meters above the ground, so when taking the accompanying documents, the train driver carries out a deep hardening of the carcass. It usually sits in front of it because it carries out preparations for driving (test of the operation of the brakes, examination of driving license documents, etc.). Suspension of the vehicle is carried out with helical springs on wheels and rubber blocks (Vrašec, 2015).

Train engine drivers are exposed to psychological stress due to possibility of person under train accidents, which cause acute psychological disturbances (Rehn et al., 2005), severe sleepiness due to night work (Szeto et al., 2007), and because of irregular shift schedules (Louit-Martinod et al., 2016).

Due to exposure to magnetic fields train engine drivers are group of professional drivers with excess risk of cancer incidence, particularly brain tumors and leukemia (Bilban, 2016). Authors also found exposure association with leukemia and Hodkin's disease (Kresal et al., 2017).

A key risk factor of myocardial infarction among train engine drivers is the combination of low decision latitude and low social support (Šprah et al., 2014). Among these, also somatic risk factors are reported as predictors of myocardial infarction, such us age, family history, low body height and systolic blood pressure (Vrašec, 2015).

From the point of view of the safety and regularity of rail transport, and on the assumption that the train ride and its associated tasks require complete 
concentration, it is understandable that mental and physical health problems in such an environment are potentially very dangerous. The smallest train engine driver's fault, which results from poor health or unwillingness, can lead to catastrophic consequences when even the lives of people, their health, or material damage are caused.

Few studies address our topic; however, no study was done among Slovene engine drivers on this topic. By this empirical research, we wanted to confirm or reject our hypotheses. The aim of our study was to investigate psychosocial risk factors among Slovene engine drivers and compare them with random Slovene professional drivers' samples in a cross-sectional study.

\section{Methodology}

For promoting health on the workplace, a new data collection tool was developed by Social Scientific Institute at the Research Centre of the Slovenian Academy of Sciences and Arts (ZRC SAZU). Since consequences of experiencing excessive stress in the workplace is so persistent and comprise a major economic burden for both employers and society. Timely detection and management of risk factors could significantly reduce this. Starting form this fact, they develop a tool, which is adapted to the special features of the Slovenian, space as well it includes the latest findings on psychosocial and other risks in working environments.

The data collection was performed between October 2016 and July 2017, by the use of a survey questionnaire. The questionnaire was distributed among drivers by the Ministry of Infrastructure of Republic of Slovenia. The cooperation in the survey was anonymous and entirely voluntary. The measurement for coping with psychosocial risks and absenteeism - OPSA, is divided into two parts 1) a general part (which includes socio demographic and health related information about the employees as well as 2) the part that focuses on employee psychosocial load evaluation. The tool enables 1) elaboration of risk assessment for the development of problems related to psychosocial stresses that are exposed to employees in the working environment, 2) analysis of the health and well-being of employees, 3) creating targeted measures for coping with psychosocial risks in 17 areas of psychosocial stress, 4) making an assessment of: experiencing excessive stress, medical absenteeism and presentism, exposure to mobbing, fluctuations, and the reasons for it and difficulties in reconciling work and family. The tool is available with a rich documentation including clear premises of data analysis of the collected data. In addition to the OPSA measuring instrument, the research team also prepared an Excel file, which is intended for data entry and evaluation, as well as the automatic assessment of psychosocial risks, their negative consequences and the development of measures for their control.

With the consensus of Social Scientific Institute ZRC SAZU, we were able to use OPSA for our research on drivers' (taxis, buses, trucks, trains drivers and others) in Slovenia psychosocial load evaluation. Our final questionnaire was an extended version of OPSA questionnaire.

According to Statistical Office of Republic of Slovenia (2018) (Table 1) in total, our population comprises 37056 professional drivers. In the sample we have the biggest share of train drivers (9.3\%), followed by taxi drivers (2.1\%) and bus drivers (1.4\%).

\section{Table 1}

Population and Sample Comparison 


\begin{tabular}{lccc}
\hline & Population & Sample & Percentage of the population \\
\hline Train drivers & 1341 & 125 & $9.3 \%$ \\
Bus drivers & 3981 & 57 & $1.4 \%$ \\
Lorry/ & 24217 & 22 & $0.1 \%$ \\
truck drivers & & 20 & $2.1 \%$ \\
Taxi drivers & 964 & 35 & $0.5 \%$ \\
Other & 6553 & $\mathbf{2 5 9}$ & $\mathbf{0 . 7 \%}$ \\
\hline Total & $\mathbf{3 7 0 5 6}$ & & \\
\hline
\end{tabular}

Source: Statistical Office of Republic of Slovenia.

However, the OPSA tool allows the input of data and their analysis only for one occupational group. We have set a task to compare the load level of drivers and other drivers, so we need a more in-depth analysis and a more detailed comparison between several groups. In the first phase, the analysis of the collected data was done according to the pre-defined OPSA guidelines, so the analysis was focused on the status review or a snapshot of the current situation. Furthermore, we went to deepen the analysis with additional hypothesis that we want to test during the research:

H1: Psychosocial risk factors (OPSA profile) are statistically significantly different between specific groups of drivers.

Due to specific working conditions, professional drivers are a group that is very exposed to health and other risks while performing their profession. When driving, due to various forced positions, the individual parts of the body are overloaded and exposed to vibrations, uncomfortable seats and limited work space. Nevertheless, the context of driving for various groups of professional drivers is very different (Bilban, 2014).

We verified the above stated hypothesis by applying analysis of variance and using IBM SPSS 24.0 software.

\section{Results and discussion}

The survey was completed by 259 drivers, mainly man (95.0\%). The drivers were aged between 31 and 65 years, the majority was between 41 and 50 years old (41.2\%), followed by the group between 51 and 65 years old (26.5\%). Among the respondents there were $48.3 \%$ train drivers, followed by $22,0 \%$ bus drivers, $8.5 \%$ were lorry/truck drivers and taxi drivers (7.7 \%), $3.5 \%$ categorized as other. The majority of the drivers were employed in the same region as they lived (82.9\%). According to health and wellbeing, 80 participants were absent from work in the last year, which is $30.8 \%$ of the whole sample. The majority were absent between 1 to 6 days ( $46.2 \%$ ), one sixth were absent between 7 and 14 days or 15 to 30 days or even more than 30 days. The most recurrent health problems were back pain (43.6\%), shoulders and neck pains (41.3\%), one fourth of the respondents $(25.1 \%)$ had problems with pain in the leg's muscles, $20.4 \%$ had mood disorder, digestion disorders (18.9\%) and sight problems (18.1 \%). The most persistent problems are interlinked with stress and work overload (40.1 \%), insomnia (33.9\%), exhaustion (32.4\%), headache (23.9\%) and lack of will (22.7 \%), muscle tension is often present $(20.0 \%)$, problems with concentration (19.3\%) and anxiety (17.3\%). The majority of the drivers believe that the above listed problems do not affect $(31.1 \%)$ or have only limited effect on day-to-day activities (39.6\%). On the other hand, stress-related problems do affect $19.6 \%$ of the participants; while $9.8 \%$ of the participants reported that stress have a great impact on day-to-day activities. More than half of the participants $(54.9 \%$ ) are satisfied with their state of health, 11.9 
$\%$ of the participants are very satisfied with their health status, not enough or dissatisfied is $22.5 \%$ of the participants, $5.9 \%$ are dissatisfied, and $4.7 \%$ of the participants are very dissatisfied with their state of health. Harmonization of professional and private life is marked as good (51.0\%), while $7.5 \%$ are very good. A good quarter of the participants (25.7 \%) assess the professional and private life balance as nor good nor bad; $12.6 \%$ of the participants assess the compliance as poor and $3.2 \%$ say that they have a very poor reconciliation of professional and private life.

Next, we checked for the willingness to make a turnover in their carriers. In the last year, $27.6 \%$ of professional drivers in our sample try to change their job. First in the line are lorry/truck drivers (55.0\%), followed by taxi drivers (47.4\%), bus drivers (43.9\%) and participants in the category "Other" $(37.1 \%)$ are most concerned about the replacement of the job, followed by. Only $9.8 \%$ of train drivers are considering changing their job. The reasons for the willing to change unfriendly working environment (71.4\%), dissatisfaction with salary (32.9\%), the nature of work (32.9\%), lack of opportunities for promotion (28.6\%), dissatisfaction with leadership (27.1\%) and lack of opportunities for further education (22.9\%).

\section{Employer's health care for employees}

Inadequate implementation of legislation in the field of labour relations and occupational safety, means that the employer carries out too little measures in the field of care for the health and safety of employees, and in the area of reducing professional stress, poor accessibility of protective equipment, poor knowledge of techniques for coping with stress (Šprah et al., 2014). In our sample (Fig 1) all occupational groups considered the employer's health concerns as good. Employers' health care is best assessed by taxi drivers $(M=3.85)$ and truck drivers $(M=3.85)$.

Figure 1

Employer's Health Care for Professional Drivers' Categories

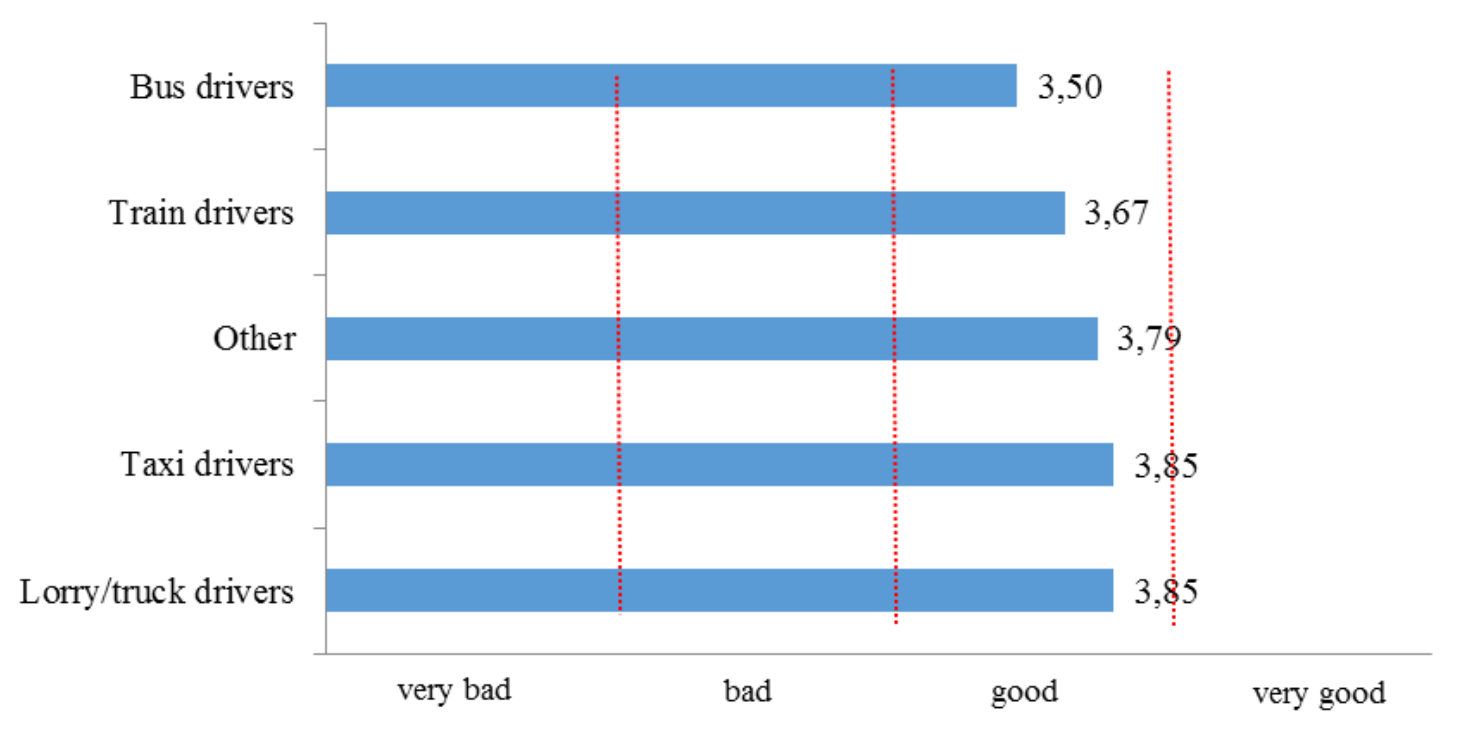

Source: Authors' illustration

Next, we asked professional drivers to rate the vulnerability of occupational groups to phenomena associated with psychosocial risks. Fig 2 shows the average vulnerability estimates for all occupational groups. According to the self-assessment, 
the participants are vulnerable to all these phenomena, with the most exposing vulnerability for experiencing excessive stress $(M=2.81)$ and the vulnerability to absenteeism ( $M=2.58)$. Šprah et al. (2014) defines:

- vulnerability for experiencing excessive stress as reflection of the imbalance when the requirements of the working environment go beyond the ability of the employee to control them;

- absenteeism as absence from work for health reasons (sick leave);

- reduced efficiency / productivity (presentism) as reduced work efficiency of employees due to health problems;

- exposure to violence in the workplace as the presence of violence or harassment at the workplace, experiencing conflicting relationships, the emergence of violations of the rules of behavior, the occurrence of abuse of superior authority, avoidance of problem solving.

Figure 2

Vulnerability Assessment for All Occupational Groups

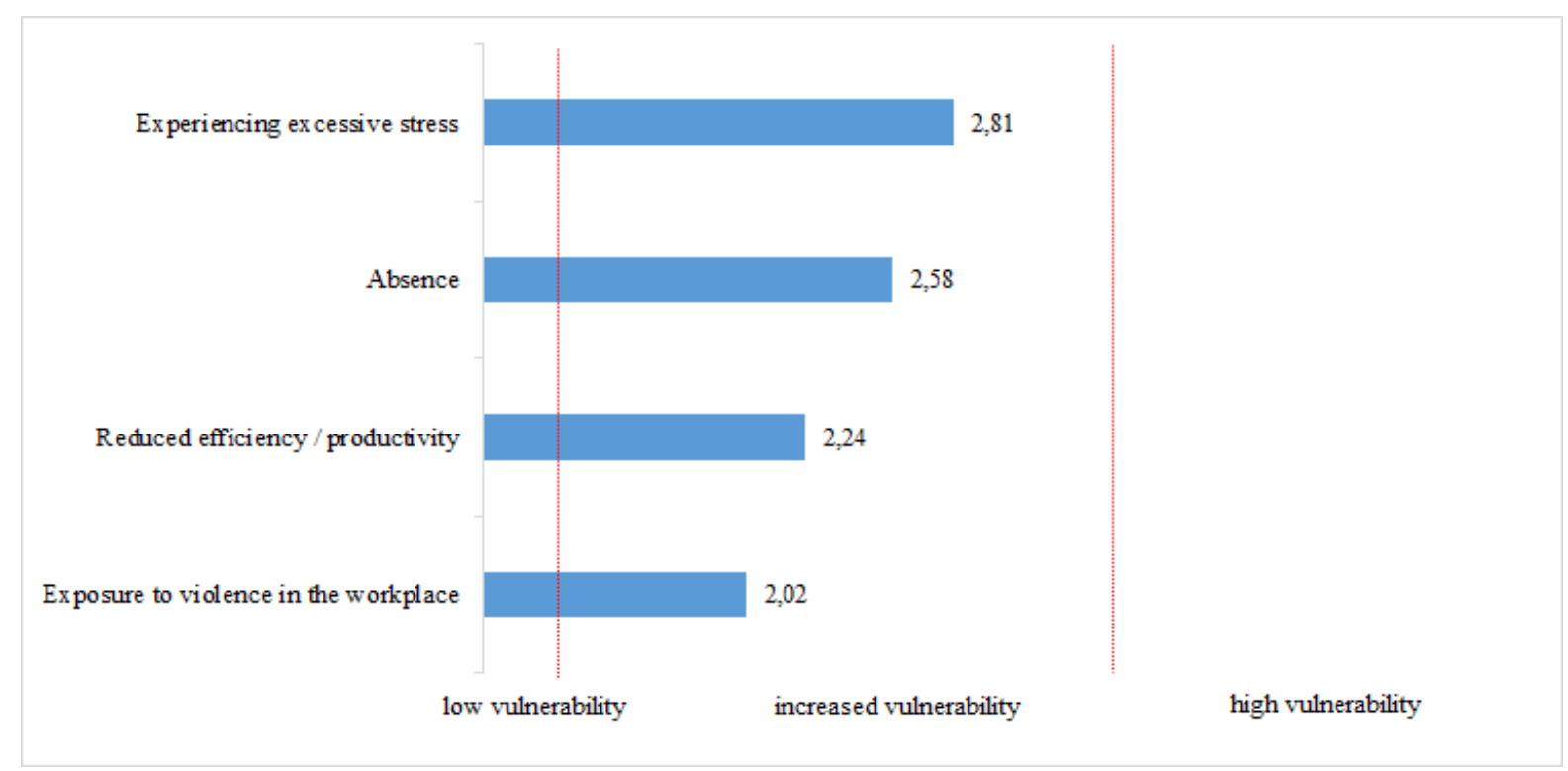

Source: Authors' illustration

The most vulnerable for experiencing excessive stress are bus drivers $(M=3.0)$ and participants in the category "Other" $(M=2.9)$, and the highest vulnerability for absenteeism is also present in bus drivers $(M=2.7)$. Drivers are the most vulnerable in the area of reduced efficiency / productivity $(M=2.3)$, while at the workplace the most exposed are bus drivers $(M=2.2)$ and taxi drivers $(M=2.2)$.

If we look at the profile of the risk areas and the extent of the load for all occupational groups of participants more closely, we can see that in the areas which pose a high risk, fall into the category of increased risk of developing excessive stress and various health problems. The highest risk is therefore in the field of work schedule $(M=3.59)$, followed by the role and responsibility of the organization $(M=3.33)$, the working environment and the load $(M=3.05)$ as well as the workload / speed of work $M=2.95)$. Although still in the category of increased risk, the lowest risk in the family situation of the employee $(M=1.76)$.

With the use of one-way analysis of variance, we tested wheatear there were statistically significant differences in OPSA statements among specific groups of 
drivers. In general, bus drivers are the group that is most vulnerable for psychosocial risk factors $(M=2.6)$, followed by train drivers $(M=2.54)$.

If we focus on specific psychosocial risk factors, the differences among groups of drivers are statistically significant for work schedule, role and responsibility in the organization, work environment and work equipment, physical loads and workload, speed of work. From Fig 3 we can see that the work schedule ( $M=4.2)$ is the most problematic element among train drivers, while role and responsibility in the organization ( $M=3.39$ ) is the most problematic element among bus drivers in Slovenia.

Figure 3

Psychosocial Risk Factors - OPSA

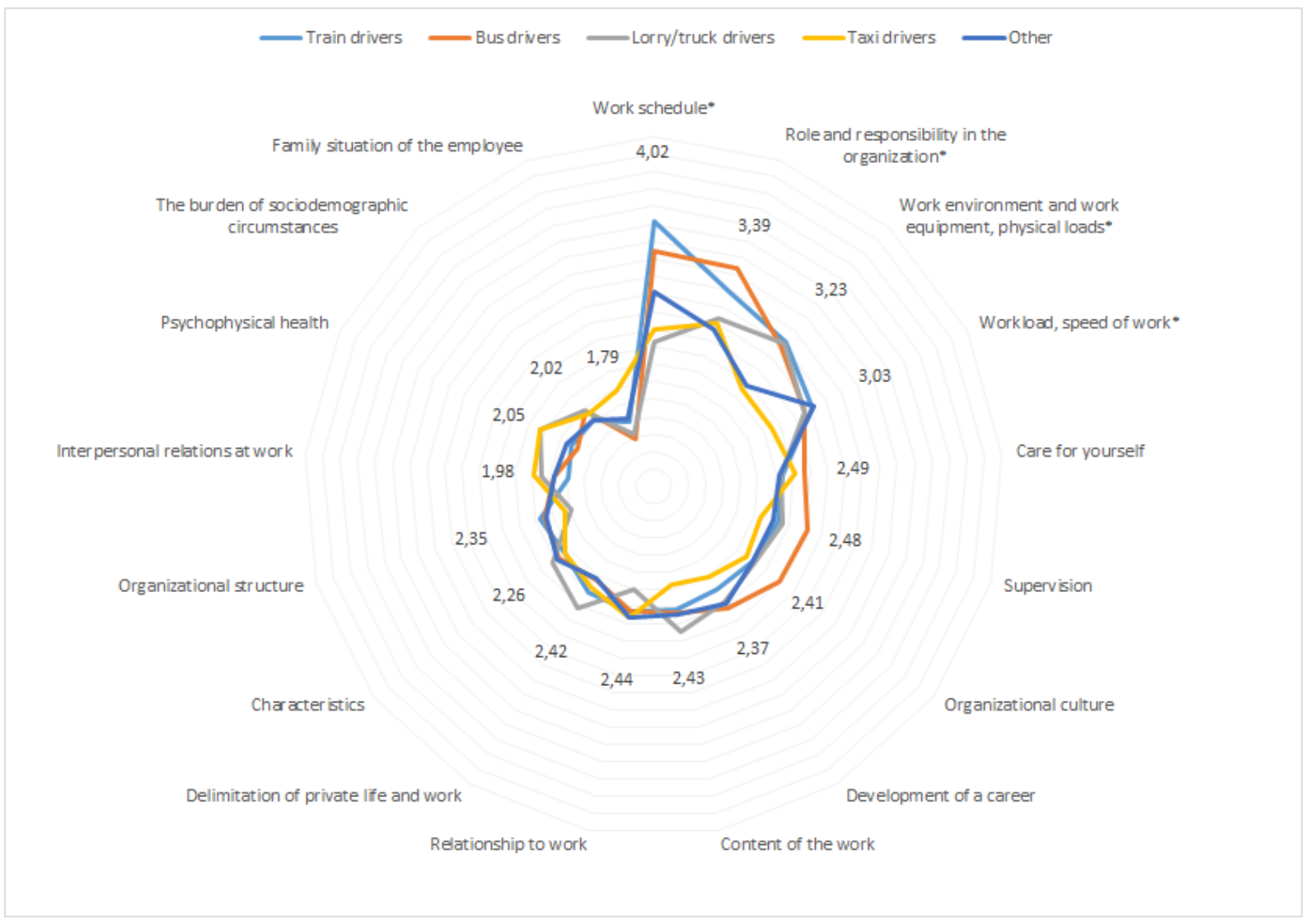

Note: *statistically significant difference at 0.05 level.

Source: Authors' illustration

To sum up, there is no evidence that the psychosocial risk factors (OPSA profile) are statistically significant different between specific groups of drivers. However, could be noted that bus and train drivers are the most vulnerability occupational groups among professional drivers.

\section{Conclusion}

With the help of the tool for managing psychosocial risks and absenteeism, we conducted a survey, which was published on www.lka.si and was active for six 
months. For answers we mainly asked drivers, as well as professional drivers of buses, taxis and trucks.

The useful contribution of the research is provided through an exploratory quantitative study. The original contribution is a quantitative survey of influential personal characteristics such as poor work habits, fear of failure at work, perfectionism, problems with the organization of time in the workplace, career development and work in general on the workload of drivers.

The final contribution helps experts and managers in the field of railway transport and, last but not least, the state as the owner of a public railway infrastructure, to help design a successful model that will lead employees to greater security in the management of individual risk factors.

The limitations of the research may be a lack of response rates, a long questionnaire, online surveying as a data collection tool, as it presents an impersonal way of capturing data.

The constraints in the survey represent a constant change in the terms of business. The findings of the research are exclusively for professional drivers in Slovenia and cannot be generalized outside of this population. The limitation is also seen in the limited sources of literature and the rare results of research in the field of the study of drivers. In future research it would be reasonable to explore the risk factors that cause absenteeism and presenteeism among professional drivers, understand them, and then focus on preventive action.

\section{References}

1. Bilban, M. (2014), Poklicni vozniki $\vee$ cestnem prometu, Zbornik predavanj, Delo in varnost.

2. Bilban, M. (2016), "Professional drivers in road transport", in Zupan, A., Bilban, M. (Eds), Evaluation of the Ability to drive a Car, Conference Proceedings, University Rehabilitation Institute RS - Soča, Ljubljana, pp. 311-320.

3. Directive 2007/59/EC (2007), of the European parliament and of the Council of 23 October 2007 on the certification of train drivers operating locomotives and trains on the railway system in the Community, Official Journal of the European Union L 148.

4. Funakoshi, M., Tamura, A., Taoda, K., Tsujimura, H., Nishiyama, K. (2003), "Risk Factors for Low Back Pain among Taxi Drivers in Japan", Sangyo Eiseigaku Zasshi, Vol. 45, No. 6, pp. 235-247.

5. Kresal, F., Bertoncel, T., Meško, M. (2017), "Psychosocial factors in the development of low back pain among professional drivers", Organizacija, Vol. 50, No. 2, pp. 151-162.

6. Louit-Martinod, N., Chanut-Guieu, C., Kornig, C., Méhaut, P. (2016), "'“A plus Dans le Bus": Work-Related Stress Among French Bus Drivers", SAGE Open, Vol. 6, No. 1.

7. NRP (National Reference Point - Nacionalno informacijsko središče) (2012), "Nacionalna poklicna kvalifikacija. Strojevodja / strojevodkinja", available at: http://www.nrpslo.org/kartica-npk.aspx/37034020 (26 March 2017).

8. Rehn, B., Lundström, R., Nilsson, T., Bergdahl, I., Ahlgren, C., From, C., Sundelin, G., Järvholm, B. (2005), "Symptoms of Musculoskeletal Disorders among Drivers of All-Terrain Vehicles in Northern Sweden", Noise \& Vibration Worldwide, Vol. 36, No. 1, pp. 13-18.

9. Statistical Office of Republic of Slovenia (2018), available at: https://www.stat.si/statweb (28 March 2018).

10. Szeto, G. P. Y., Lam, P. (2007), "Work-related Musculoskeletal Disorders in Urban Bus Drivers of Hong Kong", Journal of Occupational Rehabilitation, Vol. 17, No. 2, pp. 181198.

11. Šprah, L., Dolenc, B. (2014), Priročnik za obvladovanje psihosocialnih tveganj in absentizma s pomočjo orodja OPSA, Založba ZRC, ZRC SAZU, Ljubljana. 
12. The Criteria Committee of the New York Heart Association (1994), Nomenclature and Criteria for Diagnosis of Diseases of the Heart and Great Vessels, 9th edition, Little, Brown \& Co., Boston, pp. 253-256.

13. Vrašec, M. (2015), Vpliv delovnega mesta strojevodje vlaka na živčno-mišične funkcije trupa $\vee$ kontekstu tveganja za pojav bolečine $\vee$ spodnjem delu hrbta, Univerza na primorskem, Fakulteta za matematiko, naravoslovje in informacijske tehnologije, Koper, Slovenia.

\section{About the authors}

Danica Murko, Msc, works at the Ministry of Infrastructure. She is a PhD candidate at the Faculty of Management. Her research interests include the areas of management and human resources management. The author can be contacted at danica.murko@gov.si.

Maja Meško, PhD, has held a position as professor of management at the Faculty of management, Department of management, University of Primorska. She also has a certificate for associate professor of kinesiology (science in sport) at the Faculty of sport, University of Ljubljana. Her main teaching and research areas include management, psychology in management, organizational culture, health and sport psychology where she authored or co-authored various scientific papers. The author can be contacted at maja.mesko@fm-kp.si. 